trainees with respect to our salary structure. Those trainees who passed the MRCPsych I before and including the Spring 1996 examination moved up to the (old) registrar pay scales. However, trainees who passed later examinations continue to stagnate at senior house officer (SHO) grades. Therefore at present trainees who do the same post-MRCPsych I jobs get paid vastly differing amounts.

Such a situation is unfair and discriminatory. I have been told that the discrepancy will work itself out of the system in a couple of years - a fact which is supposed to be a source of solace to myself and others who are at the receiving end of this inconsistency. Representations to the British Medical Association and the College have not proved helpful; surprising since both organisations are in no small way responsible for the present disparity.

Entwined with the above anomaly is the fact that unlike other specialities, in psychiatry one has to pass the Part II to enter the specialist grade. While I can understand the reasons I am not sure that full attention has been paid to the financial consequences of this decision. Trainees with previous experience, either in general practice or other specialities, find their previous training does not provide the financial advantage that it would have in the past. For such trainees (and this is a significant number) the four increments on the SHO scale are used up prior to or soon after joining a SHO post.

I wonder whether account is being taken of the very obvious negative effect the above anomalies are having on recruitment and morale. I am aware of general practitioners and trainees with a medical membership who were keen to train in psychiatry, but rethought their options once aware of the financial disadvantage.

I wonder how many other trainees are aware of and are affected by these changes. A concerted effort is needed if things are to change. I would be happy to receive information about the situation in other regions from trainees at the above address.

ZUBIN BHAGWAGAR, Wellcome Research Senior House Officer, Psychopharmacology Research Unit, Warneford Hospital, University of Oxford. Headington, Oxford OX3 7JX

College's reply: Dr Bhagwagar is angry because, through no fault of his own, he was unable to pass Part I of the MRCPsych in time to move onto the (old) registrar pay scale when the specialist registrar grade was introduced last year, and is therefore being paid a lower salary than many of his contemporaries for a couple of years. He is probably also annoyed by the failure of the College and the British Medical Association to do battle with the Department of Health on his behalf over this perceived injustice. He ought to know by now, though, that life is never perfectly fair. The introduction of any major change almost always had different implications for people born, or starting university, or qualifying. or getting married a few months apart, with arbitrary winners and losers.

I doubt whether this irritating temporary anomaly is really having the effect on morale and recruitment to psychiatry he suggests. It is quite true that psychiatry has a longer mandatory period of general professional training (three years) on a relatively low SHO salary than other disciplines. But it also has a shorter specialist training than any other discipline (three years. compared with five or six years in most of the other branches of hospital medicine) and that is surely more important in the long run. Dr Bhagwagar and other readers may also be interested to know that the Court of Electors recently agreed to reduce the length of time candidates for Part II of the MRCPsych must have spent in approved training posts from three years to two and a half (of which at least two years most have been in psychiatry). As a result the time he and his successors will need to spend as SHOs before becoming specialist registrars will also be reduced by six months.

R. E. Kendell, President, Royal College of Psychiatrists, 17 Belgrave Square, London SW1X 8PG

\section{Educational supervision sessions between consultants and trainees}

Sir: The Royal College of Psychiatrists regards supervision as the "single most important ingredient of training" (Statement on Approval of Training Schemes for General Professional Training for the MRCPsych, 1992, available from the Postgraduate Education Services Department). It is therefore concerning to read Azuonye's findings that both consultants and trainees exhibited such a marked lack of understanding of the purpose of educational supervision (Psychiatric Bulletin, March 1997, 21, 154-155). We wish to draw attention to our very similar survey examining trainee supervision, previously published in the Bulletin (Herriot et al, 1994), in order to contrast our findings and comment on Azuonye's conclusions.

In contrast to the low response rates to Azuonye's questionnaire $142 \%$ of consultants and $52 \%$ of trainees), the response rate to our questionnaire was high $(83 \%$ of consultants and $67 \%$ of trainees). Whereas Azuonye found "the nature and purpose of supervision ... to be unclear to most consultants and trainees", we 
found considerable agreement between consultants and trainees on items concerning the structure and content of supervision, although a significant number of consultants and trainees were not fully satisfied with the level of individual supervision.

Although we agree with Azuonye's call for supervision to be given the high priority it deserves, we would like to suggest an alternative solution to his request for a Royal College of Psychiatrists' Special Task Force on Educational Supervision. It has previously been suggested that training schemes establish their own guidelines as to what constitutes good training and that trainees take a lead in auditing practice against these guidelines (Davies, 1993). Our project provided the basis for such a practice on the UMDS training scheme. Consultants and trainees are able to make significant improvements at a local level in the absence or anticipation of more explicit guidelines from the College. Such an approach allows the trainee and consultant to agree upon the content of supervision, and allows for the fact that some consultants may have special expertise in some areas and less knowledge in others. A centrally led dictate on supervision could be hard to implement effectively and maybe unsuited to the diversity of services, trainees and consultants.

Davies S. (1993) Consumer audit of psychiatric training. Psychiatric Bulletin, 17, 503-504.

HerRIOT, P., BHUI, K. \& LELLOTT, P. (1994) Supervision of trainees. Psychiatric Bulletin, 18. 474-476.

PETER M. HERRIOT, Noarlunga Health Services, Noarlunga Centre, South Australia 5168; KAMALDEEP BHUI, Institute of Psychiatry, London

\section{Core psychiatry for tomorrow's doctors}

Sir: The College Working Party's report on core learning in undergraduate psychiatry (Psychiatric Bulletin. August 1997, 21, 522-524) mirrors changes already taking place in medical schools throughout the UK. In Nottingham a set of learning objectives, very similar to that proposed by the working party, was devised (Cantwell \& Brewin, 1995). The list differs mainly in the realm of attitudes, an area which caused us the greatest difficulty. Unending suggestions for inclusion could be made in a discipline which students are likely to approach with a mix of attitudes based on lay misconceptions and fears. Like the working party we addressed issues about stigma, the multi-disciplinary team and the interplay between psychological and physical factors. Two other areas stood out in relation to controversies over psychiatric practice and the particular importance of the doctor-patient relationship in psychiatry. Our list is given below. (A complete list of all learning objectives given to Nottingham psychiatry undergraduates is available from the authors.)

Learning objectives, attitudes:

(a) appreciate the inter-relationship between physical and psychological symptoms and the need to be aware of psychological factors in all medical conditions:

(b) recognise the stigmatisation associated with mental illness and learning difficulties and how this can affect patients and their families;

(c) be aware of the ethical dilemmas and controversies involved in the diagnosis and management of mental disorder;

(d) appreciate the function of the multi-disciplinary team and the role of each of its members:

(e) as you progress through your attachment. acknowledge the importance of the therapeutic relationship between doctor and patient and how the time scale for change is lengthened in psychiatry.

The need to challenge perceptions of psychiatry is undeniable, and the devising of objectives relatively straightforward. We have no easy answers, however, on how such attitudinal change can be brought about in new curricula.

CANTWELL. R. \& BREWIN. J. (1995) The new undergraduate curriculum: implementing the changes in Nottingham. Psychiatric Bulletin. 19. 482-484.

Roch CANTwell, Consultant Psychiatrist and Honorary Clinical Senior Lecturer, University Department of Psychological Medicine, Gartnavel Royal Hospital, 1055 Great Western Road. Glasgow G12 OXH; and JOHN BREWIN, Consultant Psychiatrist, Department of Psychiatry, B Floor, South Block, Queen's Medical Centre, Nottingham NG7 2UH

\section{Community psychiatry in the RAF: an evaluative review}

Sir: Julian Hughes is to be congratulated on using an audit of his first six months' experience of providing community services in the Royal Air Force (RAF) to produce a provocative and thoughtful paper (Psychiatric Bulletin. July 1997, 21, 418-421). However, there are two omissions of pertinent fact. Most significantly, at the time of his audit the RAF was in the middle of major changes, almost halving its manpower. Many were facing redundancy. Given this very high level of social change, the finding of an unusually high referral rate for adjustment disorder is not too surprising and caution should 